\title{
Union Listing and the Interlibrary Loan Connection
}

\section{Kathryn Ryan-Zeugner and Mary W. Lehman}

\begin{abstract}
Analysis of unfilled interlibrary loan lending requests at the University of Notre Dame showed that $35 \%$ were for volumes not owned by the library. The library had not maintained accurate holdings records in the Indiana Union List of Serials since 1983. Incomplete and inaccurate holdings statements resulted in poor fill rates that could only worsen with time. A project to update union list holdings was launched in the spring of 1996. The project is expected to go on for five years, but the fill rate already begins to reflect the results of the corrections made.
\end{abstract}

$\mathbf{H}$ istorically, the library world has stressed the value of union lists proportionate to the proliferation of serial titles during this century. As budgets get tighter, however, the ongoing efforts to maintain union lists often fall by the wayside. Yet the increasing emphasis on consulting union lists to determine volume holdings before sending an interlibrary loan (ILL) request to another library demonstrates what would seem to be an obvious connection between holdings data and fill rates. Fill rate is defined as the percentage of the total number of requests received that are supplied by an institution, e.g., if 50 requests are supplied out of 100 received, the fill rate is $50 \%$. Improving the ILL lending fill rate is greatly dependent on the existence of accurate holdings data. In this article, we hope to reach those with the power of the purse, whose approval is required to allocate money and staff for the creation and maintenance of union lists.

Most ILL units can vouch for the fact that their use statistics rise annually. Association of Research Libraries (ARL) statistics show a $61 \%$ increase in ILL lending between 1986 and 1996 (ARL 1998). Notre Dame lending statistics show a startling 145\% increase for the same period. Additional money and staff are rarely available to cope with rising workloads. Learning to handle the work with increasing efficiency is the only answer when other help is not forthcoming. Accurate, up-to-date union lists can be critical to overburdened ILL staff.

\section{Lending Fill Rate}

Prior to beginning this project, a ten-year literature search was done on such topics as fill rates, union lists, costs, and statistics, as related to interlibrary loans. Anything that looked remotely useful was collected. In general, the literature proved disappointing. Nothing could be found on the cost of unfilled ILL requests, or on the effects of the use of union lists on ILL

Kathryx Ryax-Zeugxer (Kathryn.M.Ryan-Zeugner.1@nd.edu) is Coordinator of Interlibrary Loan, and MARY W. LehMAN (Mary.W.Lehman6@ndedu) is Head, Serials Cataloging, Hesburgh Library, University of Notre Dame, Notre Dame, Indiana. Manuscript received February 9, 1998; accepted for publication April 14, 1998. 
TABLE 1

UNFILLED INTERLIBRARY LOAN REQUESTS

(June 1985, JULY AND November 1992)

Reason Unfilled

Percentage of Total

Volume not owned

In circulation

Not on shelf

Noncirculating

Other (in process, bindery, reserve, not as cited, poor condition)

19

costs or fill rates. Review of the literature generated more questions than answers:

1. Weaver-Meyer (1995) found that $60 \%$ of ILL borrowing requests were filled by the first two libraries on the lender string, and $87 \%$ were filled within the five. No one knows how much of this is dependent on union list use, or how accurate those lists are.

2. There is debate about who should maintain union lists. A recent discussion on the ILL-L listserv came up with a variety of answers: cataloging departments, serials departments, state libraries, reference, and student assistants.

3. No figures are available on the costs for handling an unfilled request.

4. There are no figures that determine which is more cost-effective-maintaining a union list or repeatedly handling the same unfillable ILL requests.

5. It is not known what effect poorly maintained union lists might have on the effective use of Direct Request, an OCLC Online Computer Library Center, Inc. service that allows delivery of unmediated ILL requests directly into the OCLC ILL system.

These are beyond the scope of this paper.

Some believe that fill rates are significant indicators of operational activities. Although fill rates are not included in the annual ARL statistics, they do demonstrate the successful use of time spent in filling lending requests. Time is money. Libraries must give more attention to costs. Spending time on requests for materials not owned wastes money. Imagine the time wasted every day in an ILL oper- ation where $45 \%$ of incoming requests cannot be filled for various reasons.

In the early 1980s at Notre Dame, the lending fill rate hovered around $50 \%$, which seemed low. In 1985, librarians in the ILL department did a survey to determine the reasons for unfilled requests (see table $\mathbf{1}$ ). In an attempt to raise the fill rate, staff continued to search daily for items that did not appear on the shelf until the four-day OCLC time limit ran out. A check of the other reasons requests were unfilled showed that all were beyond the abilities of the ILL unit to correct. The routine rechecking of the shelves managed to inch the fill rate up to around 55\%. And there it stuck. In 1992, librarians in the unit did two additional surveys with results that were identical to the first.

\section{THE INDIANA UNION LIST at Notre Dame}

The survey results clearly showed the major obstacle to increasing the fill rate was the $35 \%$ of requests that went unfilled because Notre Dame did not own the volume. To the extent that ILL borrowers consult union list holdings data, the problem could be ameliorated if Notre Dame updated its serial holdings in the Indiana Union List (IUL). This union list was first published in paper in 1973, then microfilm, and in 1983 was added to the OCLC Union List database. Although the accuracy of the original holdings data reported by Notre Dame in 1973 is unknown, the lack of upkeep over the years can be assumed to have had a detrimental effect.

The history of union lists goes back to the middle of the nineteenth century when the first one was compiled in Italy in 
1859. The first one in this country listed the holdings of Baltimore libraries and was published in 1876 (Hanson 1968). The current situation of tight budgets and escalating serial prices should make these lists more appealing, not less. Climbing prices lead to further incentives for resource sharing, but effective resource sharing cannot be done without accurate, upto-date union lists. Besides saving time, union lists assist ILL operations in spreading the workload more equitably.

Part of the problem that led to a lack of maintenance is that union listing is seen as a cooperative project done for the benefit of other members of a consortium, not the library doing the maintenance. Accurate holdings beyond the title level didn't seem of sufficient benefit to outweigh the costs of producing them. In the early 1980 s, there was no pressure on ILL staff to use union lists. If lists were used, it was to locate a title, not a particular volume or issue. The situation has changed, and their use is now crucial to ILL operations and expected by lenders.

Because of the increased reliance on and use of ILL, ILL departments have come to rely much more heavily on union listings to speed ILL requests. Members of the Notre Dame ILL department were concerned that inaccuracies in the IUL were contributing to the low fill rate at Notre Dame. To demonstrate the inaccuracy of our holdings to the library administration, ILL staff compiled a list showing a few titles from the IUL, what the list said Notre Dame had, and what the actual holdings were. In most cases, holdings were far less than the union list indicated.

The lack of current accurate serial holdings on the IUL cost Notre Dame several offers of reciprocal agreements for free photocopies with other libraries. These libraries made the agreement contingent on accurate holdings being available on a union list, and we could not sign in good conscience with our holdings in such disarray.

In the early 1990s, as pressures grew in ILL operations, the ILL department began getting notes from some librarians who could tell that we were not always using union lists when selecting potential lenders. The pressure was growing on all
ILL operations to use union lists, and this was going to have a substantial effect on our fill rate. Where the list was in error, it almost invariably showed holdings greater than actually owned. The more that other ILL units relied on the union list, the more requests Notre Dame would receive for items not owned. Borrowing operations were willing to consult union lists because theoretically it saved them time, and provided their clients with faster service. Lending operations were interested in their fill rates, and in the time saved not searching for items not owned.

At this point it would have been helpful to have had some research on the average cost of handling an unfilled ILL request. An important consideration when making library budget decisions is whether it costs more to maintain an accurate union list even with a higher fill rate, or to check the same title over and over because of a faulty union list. Two ARL studies on ILL costs (Roche 1993, and Jackson 1998) were checked to see whether they had come up with any specific information on the cost of handling an unfilled lending request. Unfortunately, the authors of both studies focused only on determining the cost of filled ILL requests.

While the ILL department was addressing the need for a union list update project, some unanticipated questions arose from our non-ILL colleagues. They asked whether it was feasible to use the Internet to obtain borrowing request information rather than go to union lists. Accessing directly the catalogs of the world daily for hundreds of requests, however, is not nearly as efficient as searching through OCLC. The question revealed the lack of understanding of the usefulness of union lists, and the hurdles faced in assigning staff resources to maintain serial holdings.

\section{Notre Dame Union List Update Project}

When the Indiana consortium, INCOLSA, arranged in 1983 for OCLC to batch load Notre Dame's union listing data, the library's holdings were represented by about 


\section{6/ LRTS - 42(4) - Ryan-Zeugner and Lehman}

14,000 local data records (LDRs). The only maintenance on these holdings in OCLC over the following 12 years was to delete an LDR when all holdings of a listed title were withdrawn. Early in 1996, the library purchased from OCLC a printout that listed all records to which LDRs were then currently attached. Unfortunately, OCLC could not provide a listing of all the serial bibliographic records that had Notre Dame's holdings symbol attached.

A member of the library's systems staff wrote a short program to identify all records coded as bibliographic level $\mathrm{S}$ in the local NOTIS system to determine the titles to be union listed. When the program was run, the resulting printout contained just over 31,000 titles. The printout, sorted first by OCLC record number and then by local system number and title, is being annotated with the date the LDR is updated or newly created and serves as the master record of which holdings have been updated. Unfortunately, OCLC's printout is sorted alphabetically by title; it could not be sorted into OCLC record number order, which would have eased working with the two printouts side by side.

The library had already adopted the Z39.44 Serial Holdings Statements standard. Local policy for recording holdings calls for Level 4 detailed holdings. To satisfy OCLC's union listing requirement of reporting holdings at Level 3 summary holdings necessitates a reworking from Level 4 to Level 3 during rekeying into OCLC. Ensuring that the specific extent of hoidings posted to a particular OCLC bibliographic title conforms to beginning and ending dates for the title has created a buildup in the number of local bibliographic records needing remedial attention.

The NOTIS printout of serial titles to be union listed was accurate only as of the first day that union listing resumed. Subsequent serials processing that affects the accuracy of union listing must be taken into account. In order that other staff members have ready access to the information and do not incur search charges in OCLC to determine whether or how the library has union listed a title, Level 3 data without captions are entered in the local system on a copy-specific basis. Staff members in various serials workflows need only notify union listing staff of the local system's record number when there is additional work to be done in the union list.

The updating project is warmly endorsed by the library's ILL office. Outdated information is being corrected, and the library is reporting to the broader scholarly community via OCLC about holdings for thousands of titles never before union listed. It has made a positive difference; the statistics show it

\section{UNION LIST CONTRIBUTOR SURVEY}

In reading the literature on union lists, some things became obvious. Everyone who writes on the subject praises them as good and necessary-for ILL, for resource sharing, for cancellation decisions, etc. Little is written, however, on the problems of maintaining union lists. At the birth of any union list, there is much enthusiasm - but as Bloss (1985/86, 143) states, "the popularity of union list revision was second only to shelf reading."

With the knowledge that union list maintenance was low on everyone's priority list, the original contributors to the IUL were asked about their perceptions of its accuracy and completeness. Also, they were asked whether they consulted union lists in ILL borrowing and kept up their holdings once the IUL was available in the OCLC database. Using the original list of contributors found in the 1973 edition, we sent a brief survey to librarians at 56 Indiana libraries. Thirty-three librarians $(59 \%)$ responded. Of those, $25(75 \%)$ indicated that they used the IUL in placing ILL requests.

Participants were asked to give their impressions of the list's accuracy and currency. Only 10 had the courage to attempt an answer. Some of their responses were: "full of erroneous data-quicker to take a shot in the dark"; "difficult to say, but it beats an OCLC "dha' display"; "better than flying blind"; "I feel it is accurate-we do depend on it"; "spotty"; " $50 / 50$ currency, $75 / 25$ accuracy"; "I don't know"; "since we're not updating ours, we shouldn't expect others to do theirs."

Asked whether the respondent's insti- 
TABLE 2

UNFILLED INTERLIBRARY LOAN REQUESTS

(MARCH, APRIL, MAY 1997)

Reason Unfilled

Percentage of Total

Volume not owned

20

In circulation

Not on shelf

Noncirculating

tution had kept its union list holdings information up-to-date, the vote split evenly three ways: 11 yes; 11 no; and 11 partly.

Those who answered "no" or "partly" on whether their institution had kept its union listings current were asked whether they had any plans to update, and if not, why not. Some of those answers were: "too short of staff"; "lack of time"; "never use this"; "we have let it fall through the cracks"; "not a priority at this time."

One thing was apparent from the questionnaire results: the smaller libraries were the ones most likely to be maintaining their holdings. Perhaps this is because they have smaller collections to maintain and fewer changes to input annually, making labor costs less critical. Another factor for the larger institutions with large serial collections to consider was the OCLC storage costs. In 1983, the initial load into OCLC cost Notre Dame $\$ 360$. The charge is now 2 cents a year per local data record. In 1997, this came to $\$ 372$ for Notre Dame. Not bad, given 13 years of inflation.

In these days of tight budgets, all activities are scrutinized, with costs weighed against results; union listing activities are no exception. ILL costs more if you receive a large number of unfillable requests, but fixing the union list has costs, too. Without any cost data, we are suggesting, nevertheless, that it is less expensive to fix the union list. This is only a guess, but there is an underlying rationale. Once the list is up-to-date and maintained properly, there should be fewer unfillable lending requests, and ILL costs for unfilled requests should come down. If the union list is never fixed, its accuracy will further deteriorate over time, the fill rate will further decline, and the cost for unfilled requests will rise. Experience shows that requests for the same titles are received over and over again, e.g., titles of which Notre Dame owned five volumes twenty years ago, but no longer receives. Fixing and using a union list can put an end to the erroneous requests.

\section{Conclusion}

After only three months, the Notre Dame union listing maintenance project began to demonstrate its value to ILL operations. Our fill rate rose from $55 \%$ to $62 \%$, and a survey of unfilled requests showed a rather dramatic drop in the percentages for "Don't own the volume" (see table 2). These figures also demonstrate that ILL operations around the country do use union lists when selecting potential lenders. The project is now in full swing and is expected to take five years to complete.

\section{Works CITED}

Association of Research Libraries. 1998. Association of Research Libraries statistics, ed. Spencer R. Graf. Online. Available: http:// fisher.lib. virginia edu/newarl/. 18 May.

Bloss, Marjorie E. 1985/86. And in hindsight the past ten years of union listing. Serials Librarian 10, no. 1/2: 141-48.

Hanson, Eugene R. 1968. Union catalogs. In Encyclopedia of library and information science. New York: M. Dekker, 31: 415.

Jackson, Mary E. 1998. Measuring the performance of interlibrary loan operations in North American research and college libraries. Washington, D.C.: ARL.

Roche, Marilyn M. 1993. ARL/RLG interlibrary loan cost study. Washington, D. C.: ARL.

Weaver-Meyer, Pat, and Yem Fong, 1995. Interlibraryloan and document delivery: The debate over union lists. Library administration and management 9: 204-6. 